Vincent G. Te, MD

Jose M. Carnate, Jr., MD

${ }^{1}$ Department of Laboratories

Philippine General Hospital

University of the Philippines Manila

${ }^{2}$ Department of Pathology

College of Medicine

University of the Philippines Manila
Correspondence: Dr. Jose M. Carnate, Jr. Department of Pathology

College of Medicine, University of the Philippines Manila 547 Pedro Gil St. Ermita, Manila 1000

Philippines

Phone (632) 5264450

Telefax (632) 4003638

Email:jmcjpath@gmail.com

Reprints will not be available from the authors.

The authors declared that this represents original material that is not being considered for publication or has not been published or accepted for publication elsewhere, in full or in part, in print or electronic media; that the manuscript has been read and approved by the authors, that the requirements for authorship have been met by the authors, and that the authors believe that the manuscript represents honest work.

Disclosures: The authors signed disclosures that there are no financial or other (including personal) relationships, intellectual passion, political or religious beliefs, and institutional affiliations that might lead to a conflict of interest.

\section{Hyalinizing Trabecular Tumor of the Thyroid Gland}

A 34-year-old woman with a 4-year history of a slowly enlarging thyroid gland underwent a total thyroidectomy. Histologic sections showed multinodular colloid goiter. In addition, a 1.2 centimeter diameter discrete mass with a solid white cut surface was noted within the left lobe.

Sections from the left lobe mass show a well-demarcated tumor whose cells are arranged in trabecular and nested growth patterns. (Figure 1) The cells are polygonal to spindly and have ample eosinophilic, slightly granular cytoplasm and oval to angular nuclei that are often grooved. (Figure 2) Hyaline material and a delicate fibrovascular stroma surround the nests and trabeculae, and occasional psammoma bodies are seen. (Figure 3) These features led us to a diagnosis of hyalinizing trabecular tumor.

Hyalinizing trabecular tumor (HTT) is a rare thyroid neoplasm of follicular cell derivation. ${ }^{1,2}$ The tumor occurs in adults with a wide age range $\left(4^{\text {th }}-7^{\text {th }}\right.$ decades $)$ and a mean age of 47 years. It is more common in females. 'The classic histologic findings are of a solid circumscribed epithelial neoplasm with or without a thin capsule composed of medium to large-sized polygonal to fusiform cells that are arranged in alveolar, trabecular and nested groups. The cells have finely

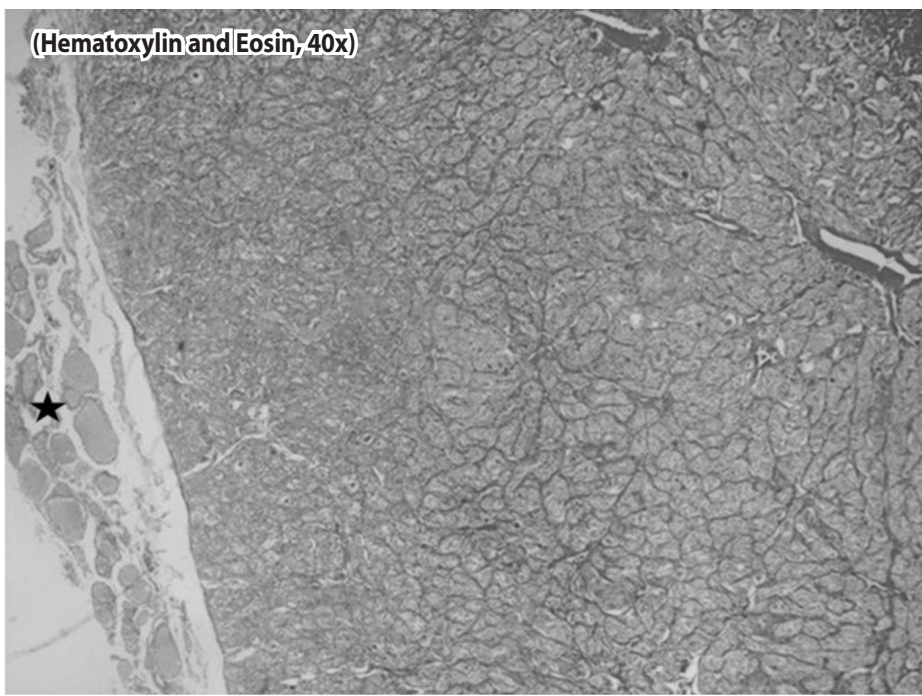

Figure 1. Hematoxylin and Eosin (40x) Well-circumscribed tumor with a nested and trabecular growth pattern and adjacent residual normal thyroid tissue (star) 


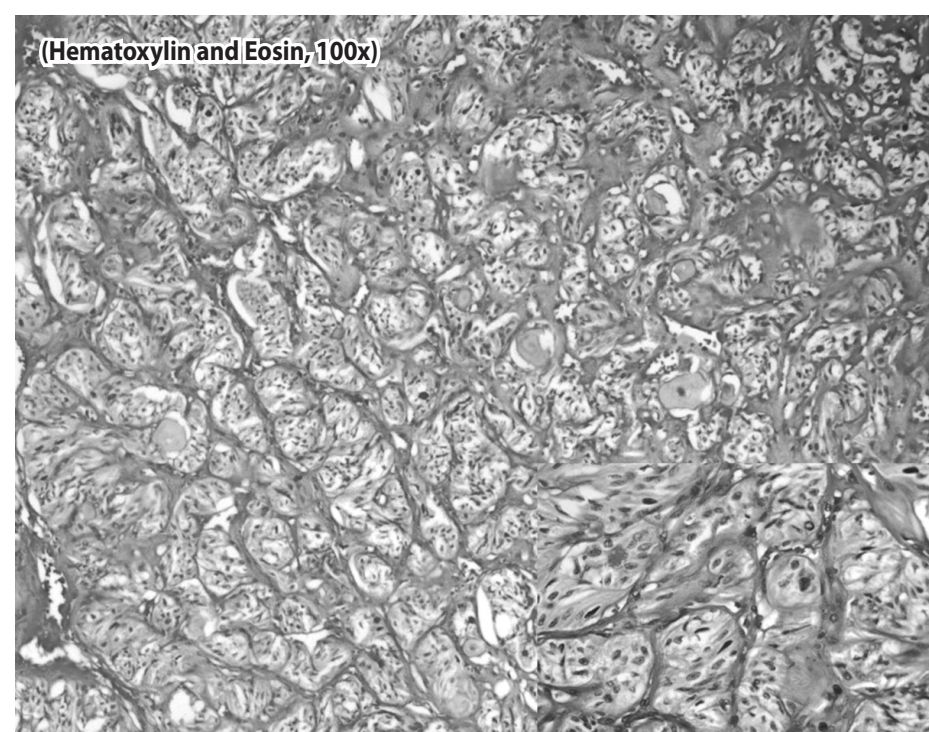

Figure 2. Hematoxylin and Eosin (100x) Nested growth pattern with hyaline material surrounding the nests; (400x Inset) Polygonal to spindly cells with eosinophilic cytoplasm and oval nuclei arranged in nests with hyaline material around the nests

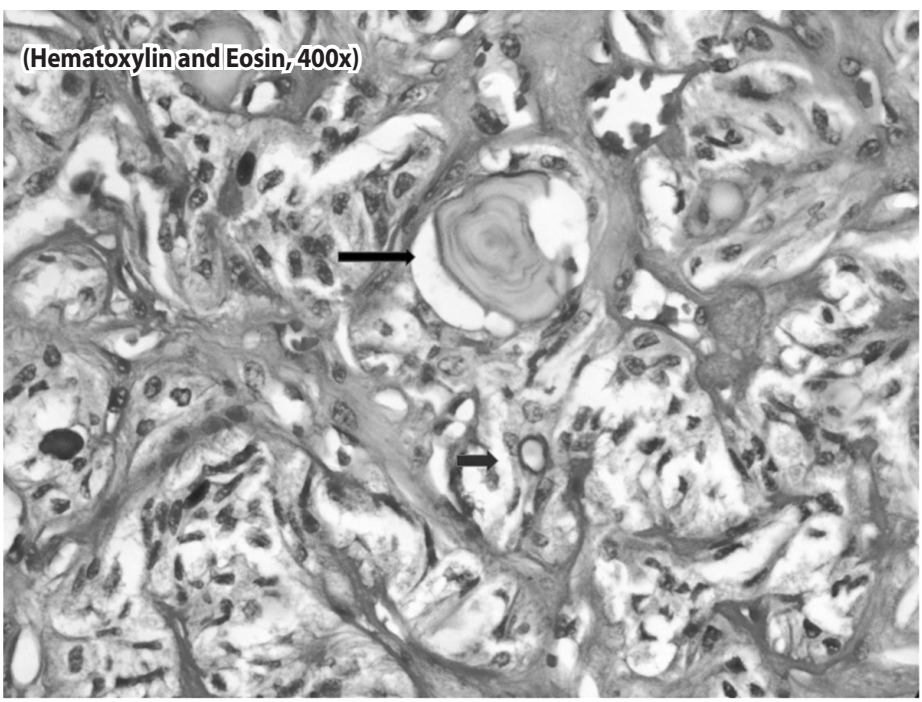

Figure 3. Hematoxylin and Eosin (400x) Polygonal to spindly cells with eosinophilic cytoplasm and oval nuclei that are often grooved. A psammoma body (long arrow) and a pseudoinclusion (short arrow) are also seen. granular, acidophilic, amphophilic or clear cytoplasm. Nuclei often have prominent grooves and small nucleoli. Calcospherites (psammoma bodies) may be present. Colloid is scant or absent. ${ }^{1,2,3}$

Because of overlapping nuclear features, a follicular variant of papillary thyroid carcinoma is a differential diagnosis. Histologic features are usually sufficient to distinguish the entities as a nestedalveolar architecture is rarely a prominent feature of a papillary carcinoma. ${ }^{2}$ Immunohistochemistry may be of aid in this distinction especially in difficult cases with limited material. Cytokeratin 19 and HBME1 are negative in HTT and are usually positive in papillary thyroid carcinomas. ${ }^{4,5,6}$ Neuroendocrine markers are also negative in HTT and are positive in medullary thyroid carcinomas and paragangliomas. ${ }^{2}$

HTT is of uncertain malignant potential and a 2008 review of 119 HTTs has shown only one case progressing to malignancy. ${ }^{3}$ The majority of cases have behaved in a benign fashion and thus may be treated conservatively.'

\section{REFERENCES}

1. Carney JA, Volante M, Papotti M, Asa S. Hyalinizing trabecular tumor. In: DeLellis, RA, Lloyd RV Heitz PU, Eng. C, editors. World Health Organization Classification of Tumours: Pathology and Genetics of Tumours of Endocrine Organs. Lyon, France: International Agency for Research on Cancer Press, 2004.

2. Gnepp DR, editor. Diagnostic surgical of the head and neck. $2^{\text {nd }}$ ed. Philadelphia: Saunders Elsevier, 2009, p. 587-88.

3. Carney JA, Hirokawa M, Lloyd RV, Papotti M, Sebo TJ. Hyalinizing trabeculart tumors of the thyroid gland are almost all benign. Am J Surg Pathol. Dec 2008; 32(12): 1877-1889. DOl 10.1097/PAS.0b013e31817a8f1b.

4. Galgano MT, Millis SE, Stelow EB. Hyalinizing trabecular adenoma of the thyroid revisited: a histologic and immunohistochemical study of thyroid lesions with prominent trabecular architecture and sclerosis. Am J Surg Pathol. 2006 Oct; 30(10):1269-73.

5. Lee $\mathrm{S}$, Hong S, Koo JS. Immunohistochemical subclassification of thyroid tumors with prominent hyalinizing trabecular pattern. APMIS. 2011 Aug; 119(8):529-36. doi: 10.1111/j.16000463.2011.02762.x. Epub 2011 May 24.

6. Hirokawa M, Carney, JA, Ohtsuki, Y. June 2000. Hyalinizing trabecular adenoma and papillary carcinoma of the thyroid gland express different cytokeratin patterns. Am J Surg Pathol.2000 Jun; 24(6):877-881. 